\title{
Use of Zinc and Oral Rehydration Solution in Home Management of Diarrhea: Knowledge of Mothers attending a Tertiary Care Hospital
}

\author{
Noshina Riaz' ${ }^{1}$, Sidra Tul Muntaha' ${ }^{1}$, Maria Qibtia², Shagufta Sohail ${ }^{1}$ \\ ${ }^{1}$ Assistant Professor, Department of Pediatrics, Yusra Medical and Dental College, Islamabad \\ ${ }^{2}$ House Officer, Department of Pediatrics, Cantonment General Hospital, Rawalpindi
}

\begin{abstract}
A B S T RACT
Background: Diarrhea is the second leading cause of mortality in children below 5 years of age in Pakistan. Use of Zinc and ORS has been proven in clinical trials to be beneficial in reducing morbidity and mortality. Poor knowledge regarding home management of diarrhea leads to mortality due to severe dehydration. The objective of this study was to assess the level of knowledge of mothers of under five-year-old children regarding, diarrheal home management in Cantonment General Hospital, Rawalpindi.

Material and Methods: This was an observational cross-sectional study carried out at Department of Pediatrics, Cantonment General Hospital, Rawalpindi, from 1st August, 2017 to 31st January, 2018. About 400 mothers of under five-year-old children, coming to the outpatient department of the hospital were enrolled in this study. A self-designed structured and validated questionnaire was used to assess the level of knowledge of mothers regarding home management of diarrhea using Oral Rehydration Solution (ORS) and Zinc. Data was analyzed using SPSS version 23 with a $p$ value $<0.05$ considered statistically significant.
\end{abstract}

Results: About $91 \%(n=364)$ of mothers had awareness regarding use of ORS as a means of diarrheal home management. Regarding level of knowledge variable results were found. A good percentage of mothers had knowledge of the purpose of ORS use $(78.3 \%)$, administration $(60 \%)$ and initiation of ORS (68\%), but only $20.8 \%$ mothers rightly answered the timing of ORS administration. Mothers knowledge about the use of zinc, daily administration and duration of administration (10-14 days) was $38.8 \%$ , $20.5 \%$ and $17.3 \%$ respectively. Mothers who were more educated especially secondary and above and of the age group $22-31$, had better awareness of ORS than others, as $P$ value is less than 0.05 . Among mothers who were aware of the use of ORS, only $41.8 \%$ of them were also aware of the use of zinc.

Conclusion: A high awareness level regarding ORS use in mothers was reflected fairly in terms of purpose, administration and initiation of ORS but the knowledge of mothers regarding use of zinc and timing of ORS administration, in home management of diarrhea is still lacking.

Key words: Diarrhea, Knowledge, Mothers, Oral rehydration solution, Zinc

Authors' Contribution:

1,2 Conception, synthesis, planning of

research and manuscript writing

Interpretation, discussion, ${ }^{3}$ Active

participations in data collection

${ }^{4}$ Data analysis.

Cite this article. Riaz N, Muntaha S, Qibtia M, Sohail S. Use of Zinc and ORS in Home

Management of Diarrhea: Knowledge of Mothers attending a Tertiary Care Hospital. J

Islamabad Med Dental Coll.2019; 8(3):135-140. doi:10.35787/jimdc.v8i3.419

\section{Introduction}

Diarrhea is the passage of three or more loose or watery stools in a 24-hour period. It can be an increase in daily stool fluidity, frequency or volume from what is considered to be normal for an individual. ${ }^{1}$ According to World Health Organization, under 5 mortality is $81.1 / 1000$ live births in Pakistan. ${ }^{2}$ This high mortality rate is attributable to diarrhea as the second leading cause of death in children after Pneumonia. ${ }^{3}$ In Pakistan, around 24 million children are under 5 year of age. An estimate of 3-4 episodes of diarrhea per year are suffered by children under 4 years of age, amounting to approximately 120 million episodes per year. ${ }^{4}$
Article info:

Received: January 22, 2019

Accepted: May 19, 2019
Funding Source: Nil

Conflict of Interest: Nil 
Preventive measures can help reduce morbidity and mortality caused by diarrhea. Primary prevention includes practicing proper hand washing, use of clean drinking water, exclusive breast feeding, immunization and good hygienic and sanitary practices. Secondary prevention includes earlier recognition and treatment of dehydration by Oral rehydration solution (ORS), frequent feeding and Zinc administration as advised by the Integrated Management of Childhood IIIness (IMCl) strategy developed by WHO.5,6 In developing countries, less than $40 \%$ of children with diarrhea receive recommended treatment and not much has been done to improve this situation. ${ }^{7}$

Since 2004, WHO and UNICEF has recommended Zinc as the only treatment to be coupled with ORS in all diarrheal episodes. Zinc is essential for protein synthesis, cell differentiation and immune function. ${ }^{8}$ Numerous clinical trials have proved that the use of Zinc along with ORS reduces the duration and severity of diarrhea and also decrease the incidence of diarrhea in the following 23 months. $^{9}$

Inadequate knowledge of mothers regarding management of diarrhea leads to mortality due to severe dehydration. ${ }^{10}$ Misbah and Rasheed carried out a study in Military Hospital, Rawalpindi and reported that only $13.5 \%$ mothers were aware of Zinc as a therapy in the management of diarrhea. However, ORS was known to $77 \%$ of mothers while $60 \%$ were familiar with the correct purpose of ORS use. ${ }^{11}$ MacDonald et al conducted household surveys in six countries upon caregiver's behavior about use of ORS and Zinc in paediatric diarrhea and found that only $12 \%$ mothers in Pakistan were aware of the correct use of Zinc. ${ }^{12}$ Diarrhea starts at home and is first managed by mothers at home. Inadequate knowledge may lead to delay in appropriate intervention. Despite the efforts of WHO in educating mothers regarding management of diarrhea with the use of ORS and Zinc, our community in general is not aware of the benefits of combined use of ORS and Zinc. This study was conducted to assess the level of knowledge of mothers of under five-year-old children regarding diarrheal home management, a step towards reducing morbidity and mortality related to diarrhea in our set-up.

\section{Material and Methods}

This observational cross-sectional study was conducted at Department of Pediatrics Cantonment General Hospital, Rawalpindi from $1^{\text {st }}$ August 2017 to 31 January 2018. Non-probability consecutive sampling technique was used for sample collection. All mothers of under fiveyear-old children coming to outpatient department in Cantonment General hospital were included in study. Informed written consent was taken from parents of participants. Sample size was calculated by WHO sample size calculator, at $95 \%$ confidence level, $5 \%$ absolute precision and anticipated population proportion of $61.7 \% \cdot{ }^{13}$ Although the calculated sample size was 364 , in order to improve the validity of data a total of 400 mothers were enrolled in this study.

This study was approved by the Ethical Review Board of Yusra Medical \& Dental College, Islamabad. A selfdeveloped structured questionnaire was used for data collection $^{1}$ and validated for this study with a reliability of 0.78 Cronbach Alpha. This questionnaire was used to assess the level of knowledge of home management of diarrhea using ORS and Zinc. Educational status, maternal age and source of information of mothers was noted. Education was categorized into Primary (until $8^{\text {th }}$ grade), Secondary (9-12 grades) and Tertiary (Graduate or above) levels. Data was analyzed by using SPSS version 23. For descriptive variables like maternal age and educational level, frequencies and percentages were calculated. Chi square test was used for categorical comparisons with a $p$ value $<0.05$ considered statistically significant.

\section{Results}

Major source of information for mothers were health workers $(55.8 \%)$ followed by family members $(27.3 \%)$ with media as a poor source of information (2.8\%), while $14.3 \%$ of mothers had no information at all regarding diarrheal home management. The awareness and level of knowledge of mothers regarding use of oral rehydration solution is shown in Table I.

Table II states poor level of knowledge of mothers regarding use of zinc in home management of diarrhea. 
Mothers knowledge about the use of zinc, daily administration and duration of administration (10-14 days) was $38.8 \%, 20.5 \%$ and $17.3 \%$ respectively.

\begin{tabular}{|c|c|c|c|}
\hline \multicolumn{4}{|c|}{$\begin{array}{c}\text { Table I: Awareness of mothers regarding use of ORS in } \\
\text { Diarrheal Home Management }\end{array}$} \\
\hline & & Yes & No \\
\hline \multicolumn{2}{|c|}{$\begin{array}{l}\text { Have you heard of oral rehydration solution as } \\
\text { a means of managing childhood diarrhea at } \\
\text { home? }\end{array}$} & $\begin{array}{c}364 \\
(91 \%)\end{array}$ & $\begin{array}{c}36 \\
(9 \%)\end{array}$ \\
\hline \multicolumn{4}{|c|}{$\begin{array}{l}\text { Respondents' knowledge of Diarrheal Home management: Use of } \\
\text { ORS }\end{array}$} \\
\hline Items & Variables & \multicolumn{2}{|c|}{$\mathrm{n}(\%)$} \\
\hline \multirow{5}{*}{$\begin{array}{l}\text { The Purpose } \\
\text { of ORS is to }\end{array}$} & Stop diarrhea & \multicolumn{2}{|l|}{$25(6.3)$} \\
\hline & $\begin{array}{l}\text { Reduce the duration of } \\
\text { diarrhea }\end{array}$ & \multicolumn{2}{|l|}{$12(3)$} \\
\hline & $\begin{array}{l}\text { Replace the body salts, energy } \\
\text { and water lost in diarrhea }\end{array}$ & \multicolumn{2}{|c|}{$313(78.3)$} \\
\hline & Prevents diarrhea & \multicolumn{2}{|l|}{$4(1)$} \\
\hline & I don't know & \multicolumn{2}{|c|}{$46(11.5)$} \\
\hline \multirow{4}{*}{$\begin{array}{l}\text { ORS is given } \\
\text { with }\end{array}$} & Feeding bottle & \multicolumn{2}{|c|}{ 107(26.8) } \\
\hline & Cup and spoon & \multicolumn{2}{|l|}{$240(60)$} \\
\hline & By force feeding & \multicolumn{2}{|l|}{$20(5)$} \\
\hline & I don't know & \multicolumn{2}{|l|}{$33(8.3)$} \\
\hline \multirow{4}{*}{$\begin{array}{l}\text { How soon } \\
\text { should the } \\
\text { use of ORS } \\
\text { start? }\end{array}$} & After two days of watery stool & \multicolumn{2}{|l|}{$44(11)$} \\
\hline & After three days & \multicolumn{2}{|l|}{$11(2.8)$} \\
\hline & $\begin{array}{l}\text { Soon after the first/second } \\
\text { motion of watery stool noticed }\end{array}$ & \multicolumn{2}{|l|}{$272(68)$} \\
\hline & I don't know & \multicolumn{2}{|c|}{$73(18.3)$} \\
\hline \multirow{6}{*}{$\begin{array}{l}\text { Timing of } \\
\text { ORS } \\
\text { administratio } \\
\mathrm{n} \text { : It is given }\end{array}$} & Every hour & \multicolumn{2}{|c|}{$59(14.8)$} \\
\hline & After each bowel motion & \multicolumn{2}{|c|}{$83(20.8)$} \\
\hline & After vomiting & \multicolumn{2}{|l|}{$10(2.5)$} \\
\hline & $\begin{array}{l}\text { To prevent diarrhea before it } \\
\text { starts }\end{array}$ & \multicolumn{2}{|l|}{$3(0.8)$} \\
\hline & Frequently & \multicolumn{2}{|c|}{$183(45.8)$} \\
\hline & I don't know & \multicolumn{2}{|c|}{$62(15.5)$} \\
\hline
\end{tabular}

\begin{tabular}{|l|l|c|}
\hline \multicolumn{3}{|c|}{$\begin{array}{c}\text { Table II. Awareness of mothers regarding use of Zinc in } \\
\text { Diarrheal Home Management }\end{array}$} \\
\hline \multicolumn{1}{|c|}{ Items } & \multicolumn{1}{|c|}{ Variables } & $\mathrm{n}(\%)$ \\
\hline \multirow{2}{*}{$\begin{array}{l}\text { Zinc tablet or suspension is } \\
\text { used for children with diarrhea }\end{array}$} & Yes & $155(38.8)$ \\
\cline { 2 - 3 } & I don't know & $245(61.3)$ \\
\hline Zinc is given & Daily & $82(20.5)$ \\
\cline { 2 - 3 } & Twice daily & $31(7.8)$ \\
\cline { 2 - 3 } & Thrice daily & $27(6.8)$ \\
\cline { 2 - 3 } & Four times daily & $1(0.8)$ \\
\cline { 2 - 3 } & I don't know & $259(64.8)$ \\
\hline Zinc is given for duration of & 3 days & $10(2.5)$ \\
\cline { 2 - 3 } & 5 days & $17(4.3)$ \\
\cline { 2 - 3 } & 7 days & $29(7.3)$ \\
\cline { 2 - 3 } & 10-14 days & $69(17.3)$ \\
\cline { 2 - 3 } & I don't know & $275(68.8)$ \\
\hline
\end{tabular}

Mothers who were more educated especially secondary and tertiary level, with an age group of 22-31 years, had better awareness of ORS than others $(P<0.05)$ (Figures 1 and 2). The mothers who were aware regarding the use of ORS for diarrhea, only $41.8 \%$ of them were also aware of the use of zinc (Table III).

\begin{tabular}{|c|c|c|c|c|}
\hline \multicolumn{5}{|c|}{$\begin{array}{l}\text { Table III. Comparison of Awareness level of ORS } \\
\text { Zinc in Diarrheal Home Management }\end{array}$} \\
\hline & & \multicolumn{2}{|c|}{ Use of Zinc } & \multirow{2}{*}{$P$-Value } \\
\hline & & Yes & I don't Know & \\
\hline \multirow{2}{*}{$\begin{array}{l}\text { Awareness } \\
\text { of ORS }\end{array}$} & Yes & $41.8 \%$ & $58.2 \%$ & \multirow[b]{2}{*}{0.00} \\
\hline & No & $8.3 \%$ & $91.7 \%$ & \\
\hline
\end{tabular}

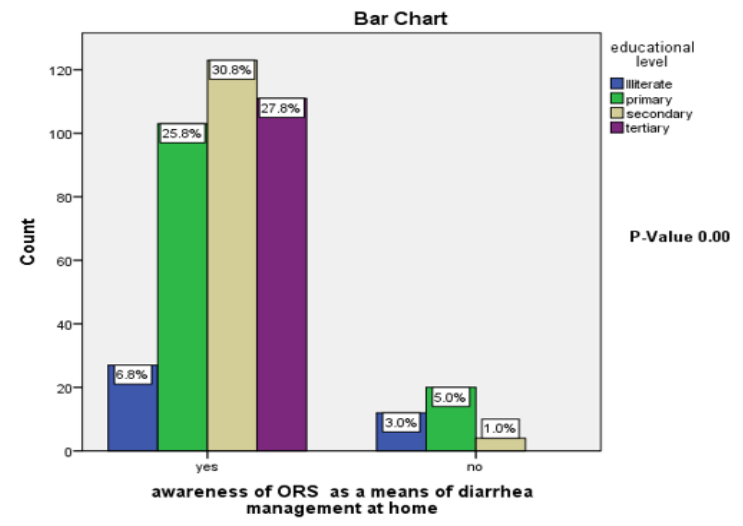

Figure 1: Impact of educational status of mothers on awareness of ORS use.

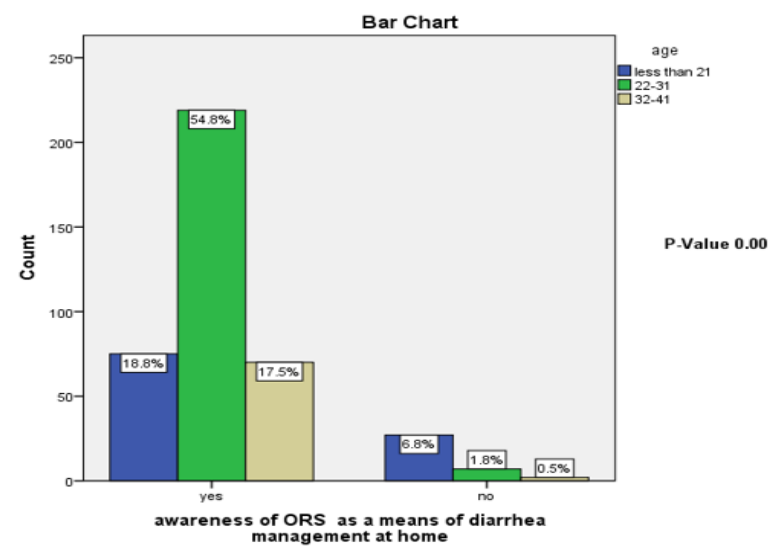

Figure 2: Relation of Age with Awareness level of ORS.

\section{Discussion}

Our study reveals good awareness regarding use of ORS amongst mothers of under five-year-old children, for diarrheal home management but the level of knowledge for the use of ORS showed variable results. Mothers had adequate knowledge of the purpose, administration and 
initiation of Oral rehydration solution but less than one fourth of the mothers rightly stated the timing of ORS administration. Poor knowledge regarding the use of zinc, daily administration and duration of administration (10-14 days) was found in our study population.

A study conducted in Nigeria by Olatona et al. ${ }^{8}$ showed consistent results with our study as far as awareness level of ORS and knowledge of zinc is concerned. But the level of knowledge of ORS use showed mix results. As in their study $51.4 \%$ mothers knew the purpose of ORS as compared to $78.5 \%$ mothers in our study. Knowledge about administration of ORS in our study was found in $60 \%$ of mothers, in comparison to $80.9 \%$ mothers in the Nigerian study. Similarly, our study revealed a higher percentage of mothers $(68 \%)$ with a sound knowledge on how soon ORS should be administered as compared to the Nigerian mothers (54.6\%). Knowledge regarding timing of ORS use was poor in both studies. ${ }^{8}$ Masiha et al in their study in Holy Family Hospital, Rawalpindi reported that $81.7 \%$ mothers were aware of ORS use in Diarrhea and $37.6 \%$ knew the correct timing in contrast to $91 \%$ and $20.8 \%$ respectively in our study. ${ }^{4}$

Shahzad et al conducted a survey in three Tertiary care hospitals of Lahore and found management of diarrhea was greatly influenced by the information transferred by family members $(64.30 \%)$. Health care workers were a poor source $(16.7 \%)$, while $14.3 \%$ were unaware of the management. These findings are contradictory to our results as major source was healthcare workers followed by relatives and then media. While similar percentage of mothers were unaware of the management in our study. Correct timing of ORS administration was almost similar in both studies, $29 \%$ in the former and $20.8 \%$ in the latter study, respectively. ${ }^{13}$

Akhtaruzzaman et al. ${ }^{14}$ concluded in a study conducted in Bangladesh that $90 \%$ mothers used ORS while only $35.5 \%$ mothers used zinc in diarrheal episodes and these results are consistent with our study. Contrasting results were found with a study conducted in Chandragiri by Maheswari et al., as $100 \%$ participants were aware of zinc supplementation. ${ }^{15}$

Tariq et al found consistent awareness level of Zinc use in diarrhea among mothers in Peshawar $36.7 \%$ versus
$38.8 \%) .{ }^{16}$ Kalsoom et al found $61 \%$ mothers at Fauji Foundation Hospital in Rawalpindi were aware of correct timing of ORS administration that is quite high compared to our study $(20.8 \%) .^{17}$

Dhar et.al reported that only $1.9 \%$ of the respondents were aware of zinc use in diarrhea in a study conducted in India. This knowledge corresponded to the educational level of mothers as higher the level, more was the awareness observed. ${ }^{18}$ This finding was also consistent with our study. Gwarzo conducted an awareness study of zinc use in North western Nigeria and found that 55.7\% mothers were well aware of it. ${ }^{19}$ This awareness level is higher than our study, most probably due to difference in the level of maternal education. Health facilities were the main sources of information for $55.9 \%$ mothers as found in our study (55.8\%). ${ }^{19}$ Padhy et.al in Southern Odisha, India found that only $1 \%$ of mothers had good knowledge of zinc therapy. ${ }^{20}$ This level is very low as compared to our study.

Ogunrinde et al found comparable results of awareness level of zinc (32\%) in Northwestern Nigeria, but the overall knowledge of home management of diarrhea was found to be less than $1 \%$, that is quite low as compared to our study. ${ }^{21}$ Mosweu conducted a survey in Botswana and found that $84.5 \%$ of mothers were aware of ORS use and $41.7 \%$ practiced Zinc supplementation in home management of diarrhea respectively. ${ }^{22}$ These observations are comparable to our results.

Ali et.al assessed the effectiveness of the 7-point diarrhea control strategy of WHO and UNICEF in Uttar Pradesh, India and observed lower levels of awareness of use of ORS and zinc for diarrhea. About $69.3 \%$ mothers knew about ORS use and only $18.5 \%$ mothers had heard of Zinc use in diarrhea. ${ }^{23}$

In a nutshell we need mass awareness campaigns regarding Diarrheal home management, as knowledge will affect the behavior of masses. Use of Zinc still needs to be incorporated in our community as low awareness levels were found. 


\section{Conclusion}

A high awareness level regarding ORS use in mothers was reflected fairly in terms of purpose, administration and initiation of ORS, but the timing of ORS administration and knowledge of mothers regarding use of zinc in home management of diarrhea is still lacking.

\section{References}

1. Olopha OO, Egbewale B. Awareness and Knowledge of Diarrheal Home Management among Mothers of Under-five in Ibadan, Nigeria. Universal J Public Health. 2017; 5(1): $40 \quad-\quad 5 . \quad$ Doi: 10.13189/ujph.2017.050106

2. World Health Organization. Global Health Observatory. Geneva: World Health Organization; 2017. http://apps.who.int/gho/data/node.cco.

3. Salmanuddin, Shah I, Arif S, llyas A. Mother's Knowledge and Attitude Associated with Diarrhea in an Urban Area in Karachi, Pakistan. Int J Innov Res Dev. 2015; 4(5): 138-41.

4. Masiha SA, Khalid A, Malik B, Shah SMA. Oral Rehydration Therapy- Knowledge, Attitude and Practice (KAP) Survey of Pakistani Mothers. JRMC Students Supplement. 2015;19(S-1):51-54.

5. Rokkappanavar KK, Nigudgi SR, Ghooli S.A study on knowledge and practice of mothers of under-five children regarding management of diarrhoea in urban field practice area of MRMC, Kalaburagi, Karnataka, India. Int J Community Med Public Health. 2016; 3(3): 705-10. Doi: 10.18203/2394-6040.ijcmph20160637

6. Amare D, Dereje B, Kassie B,Tessema M, Mullu G, Alene $B$, et al. Maternal Knowledge and Practice Towards Diarrhoea Management in Under Five Children in Fenote Selam Town, West Gojjam Zone, Amhara Regional State, Northwest Ethiopia. J Infect Dis Ther. 2014 ;2(6): 182. Doi:10.4172/23320877.1000182

7. Hemant J,Bamnawat S. Knowledge and attitude towards oral rehydration therapy among mothers of under-five children of South Rajasthan, India. Int J Contemp Pediatr. 2016; 3(2): 394-397. Doi: 10.18203/2349-3291.ijcp20161021

8. Olatona FA, Obrutu OE, Adeniyi OF.Home Management Of Childhood Diarrhea Including Zinc Supplementation Among Mothers Attending Primary Health Centers In An Urban Community In Lagos. TJHS. 2016; 23 (2): 23-29.
9. Omuemu VO, Ofuani IJ, Kubeyinje IC. Knowledge and Use of Zinc Supplementation in the Management of Childhood Diarrhea among Health Care Workers in Public Primary Health Facilities in Benin-City, Nigeria. Glob J Health Sci .2012; 4(2): 68-76. Doi: 10.5539/gjhs.v4n2p68

10. Mumtaz $Y$, Zafar M, Mumtaz Z. Knowledge attitude and practices of mothers about diarrhea in children under 5 years. J Dow Uni Health Sci. 2014; 8(1): 3-6.

11. Misbah S, Rasheed K. Maternal Knowledge and Management Skills about Diarrhea among Children under 5 Years of Age. 2016 13th International Bhurban Conference on Applied Sciences and Technology (IBCAST), Islamabad. 2016: 92-95. Doi: 10.1109/IBCAST.2016.7429860.

12. MacDonald V, Banke K, Sanders E. Encouraging Caregiver Use of Zinc and ORS for the Treatment of Pediatric Diarrheas. EJNFS. 2015. http://www.journalejnfs.com/index.php/EJNFS/article/ view/27853

13. Shahzad S, Farooq SA, Noor A, Batool SF, Alvi QA, Amir T, et al. Association of Maternal Knowledge and Practices Regarding Prevention and Care of Diarrhea at Home for Children less than 5 years of Age: A Study Conducted in Tertiary Level Hospitals of Lahore, Pakistan. Int Arch BioMed Clin Res. 2018; 4(2): 68-72. Doi:10.21276/iabcr.2018.4.2.21

14. Akhtaruzzaman M, Hossain MA, Khan RH, Karim MR, Choudhury AM, Islam MS, et al. Knowledge and practices of mothers on childhood diarrhea and its management attended at a tertiary hospital in Bangladesh. Mymensingh Med J. 2015; 24(2): 26975. PMID: 26007253

15. Maheswari MU, Sreelatha M, Sudharani P. A Study to Assess the Knowledge and Practices Regarding ORT for Acute Diarrhea among Mothers of Under Five Children in RHC, Chandragiri. JNMMH. 2016; 2(2): 75-80. Doi: 10.21088/jnmmh.2454.7506.2216.6

16. Tariq M, Khanzada A, Aram A, Naeem A, Ahmad B, Rauf $A M$, et al. Diarrhea in children: health-seeking behavior of parents attending a rural community hospital of Peshawar, Khyber Pakhtunkhwa, Pakistan. J Med Students. 2015; 1(2): 26-32.

17. Kalsoom U, Amjad T, Bairam S. Assessment of knowledge about diarrhea and its home management in mothers of under five-year children attending a tertiary care hospital. Pak Armed Forces Med J. 2018; 68(3): 550-55.

18. Dhar DK, Majumder N, Paul D. Assessment of knowledge and practice of mothers of children under 
five regarding zinc therapy in childhood diarrhea. Int J Adv Integ Med Sci.2016; 1(4): 169-172. Doi: 10.5005/jp-journals-10050-10055.

19. Gwarzo GD. Mothers' awareness and use of zinc in under-five children with diarrhea in North-Western Nigeria. Niger J Paediatr. 2018; 45 (2): 81 - 85. Doi: 10.4314/njp.v45i2.2

20. Padhy S, Sethi RK, Behera N. Mother's knowledge, attitude and practice regarding prevention and management of diarrhoea in children in southern Odisha. Int J Contemp Pediatr. 2017; 4: 966-71. Doi: 10.18203/2349-3291.ijcp20171708

21. Ogunrinde OG, Raji T, Owolabi OA, Anigo KM. Knowledge, attitude and practice of home management of childhood diarrhea among caregivers of under-5 children with diarrheal disease in Northwestern Nigeria. J Trop Pediatr. 2012; 58(2): 143-6. Doi: 10.1093/tropej/fmr048

22. Mosweu GJ. Knowledge, attitude and practices of caregivers (KAP) on management of childhood diarrhea among children aged between 0-5 years attending child welfare clinic (CWC) in Mogoditshane Village, Botswana. MSc[dissertation]. Johannesburg: University of the Witwatersrand, Johannesburg; 2018. URI: https://hdl.handle.net/10539/25229.

23. Ali F, Singh OP, Dutta A, Haq ZU, Ghatak A, Ashtankar T. Assessing critical gaps in implementation of WHO and UNICEF'S 7-point diarrhea control and prevention strategy in Uttar Pradesh, India. Ann Trop Med Public Health .2017; 10: 571-9. 